\title{
BURST PRESSURE FAILURE OF TITANIUM TANKS DAMAGED BY SECONDARY PLUMES FROM HYPERVELOCITY IMPACTS ON ALUMINUM SHIELDS
}

\author{
H. Nahra ${ }^{1}$, L. Ghosn ${ }^{1}$, E. Christiansen ${ }^{2}$, B.A. Davis ${ }^{2}$, \\ C. Keddy ${ }^{3}$, K. Rodriguez ${ }^{3}$, J. Miller ${ }^{4}$ and W. Bohl ${ }^{4}$ \\ ${ }^{I}$ NASA- Glenn Research Center, 21000 Brookpark Rd., Cleveland, OH 44135 \\ ${ }^{2}$ NASA Johnson Space Center, 2101 NASA Parkway, Mail Code SX2, Houston, TX 77058 \\ ${ }^{3}$ NASA White Sands Test Facility, P.O. Box 20, Las Cruces, NM 88004-0020 \\ ${ }^{4}$ Lockheed Martin, Space Systems Co., P.O.Box 179, Denver, Colorado, 80201, USA
}

\begin{abstract}
Metallic pressure tanks used in space missions are inherently vulnerable to hypervelocity impacts from micrometeoroids and orbital debris; thereby knowledge of impact damage and its effect on the tank integrity is crucial to a spacecraft risk assessment. This paper describes tests that have been performed to assess the effects of hypervelocity impact (HVI) damage on Titanium alloy (Ti-6Al-4V) pressure vessels burst pressure and characteristics. The tests consisted of a pair of HVI impact tests on water-filled Ti-6Al-4V tanks (water being used as a surrogate to the actual propellant) and subsequent burst tests as well as a burst test on an undamaged control tank. The tanks were placed behind Aluminum (Al) shields and then each was impacted with a $7 \mathrm{~km} / \mathrm{s}$ projectile. The resulting impact debris plumes partially penetrated the Ti-6Al-4V tank surfaces resulting in a distribution of craters. During the burst tests, the tank that failed at a lower burst pressure did appear to have the failure initiating at a crater site with observed spall cracks. A fracture mechanics analysis showed that the tanks failure at the impact location may have been due to a spall crack that formed upon impact of a fragmentation on the Titanium surface. This result was corroborated with a finite element analysis from calculated Von-Mises and hoop stresses.
\end{abstract}

Keywords: Hypervelocity impacts, plume ejecta, depth of penetration, fracture, Stress Intensity Factor, toughness.

PACS: $96.24 . \mathrm{Pq}, 62.20 . \mathrm{mm}$.

\section{INTRODUCTION}

Metallic and composite surfaces of high pressure vessels (pressurant tanks) and propellant tanks are vulnerable to exposure to hypervelocity impacts from secondary plumes that are generated from primary impacts on the outer surfaces of a spacecraft. In a spacecraft Micrometeoroids and Orbital Debris (MMOD) risk assessment, a critical depth of penetration criterion is usually assigned to each vulnerable surface. If a predicted depth exceeds the assigned limit, the surface is deemed to be a failure with an assumption in a loss of mission or a loss of crew. The motivation of this work is to establish a process to determine/assess Micrometeoroids and Orbital Debris damage criteria on metal and composite pressure vessels based on analyses and tests. HVI tests were first performed on biaxially stressed coupons in order to assess the stress effects on craters depth and materials. The tests described here used HVI and subsequent pressure burst tests of Titanium tanks to identify the threshold depth of penetration criterion for metallic tanks. 


\section{EXPERIMENTS}

\section{Hypervelocity Impact Testing}

The two HVI tests reported here have been performed at NASA White Sands Testing Facility (WSTF). Each test consisted of launching a particle at about $7 \mathrm{~km} / \mathrm{s}$ at an aluminum shield behind which an unpressurized titanium tank partially filled with water was fixed in a an orientation normal with respect to the ejected secondary plume from the first penetration through the aluminum shield. Figure 1 shows a basic schematic of the HVI tests. The projectiles for the two HVI tests were $1.6 \mathrm{~mm}$ Aluminum and $3.6 \mathrm{~mm}$ Nylon at $~ 7$ $\mathrm{km} / \mathrm{s}$. A scan of the tank thickness was performed on the two tanks before impact for proper tank orientation and post testing surface characterization. The thickness ranged from 0.04" to 0.1 " from the welding joint to the boss. The goal was to achieve depths of penetration ranging from 10 to about $40 \%$ for the two impacting projectiles.

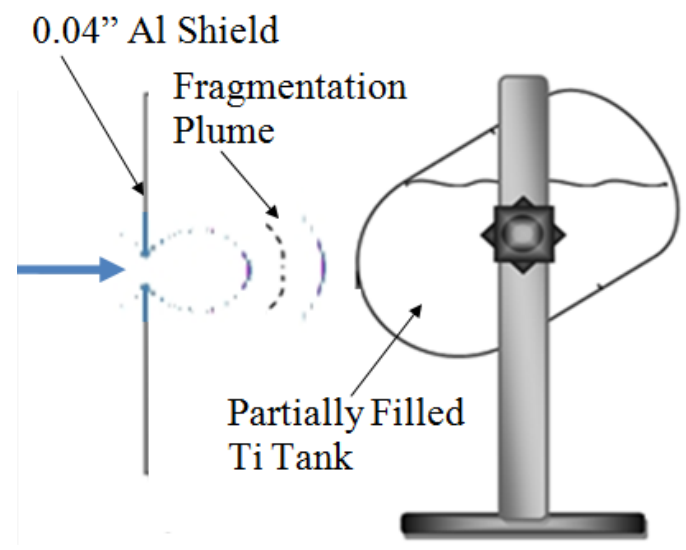

Figure 1. Schematic of the hypervelocity impact on the titanium tanks partially filled with water.

\section{Pressure Burst Testing}

In order to assess the effects of cratering on the burst pressure of the tanks, a series of three burst pressure tests were performed on the two HVI-damaged and one undamaged tank. During pressurization, the pressure as a function of time was recorded. Moreover, two biaxial strain gages were used to record the local strain as the tank was pressurized. One of the strain gages was positioned at the damaged area and the other positioned opposite from the first on the same meridian.

\section{RESULTS}

\section{Hypervelocity Impact}

\section{Al $1.6 \mathrm{~mm}$ projectile on shielded \#0062 tank}

Unexpectedly high damage to the tank \#0062 was induced from the aluminum $1.6 \mathrm{~mm}$ projectile launched at $7 \mathrm{~km} / \mathrm{s}$. This was due to the late separation of the projectile carrier "Sabot," The late separation resulted in pieces of the sabot impacting the 0.04" thick aluminum shield, and consequently more fragmentation impacted the titanium tank and resulted in craters that were over $50 \%$ depth of penetration.

\section{Nylon $3.6 \mathrm{~mm}$ projectile on shielded \#0092 tank}

The nylon projectile, unlike the aluminum projectile was launched successfully and impacted the aluminum 0.04" shield resulting in a perforation and aluminum fragments ejecting from the target at reduced velocity and impacting the tank surface. The distribution of the crater was uniform over the surface and that is attributed to the melting and vaporization of the nylon projectile upon impact. This was also observed in previous HVI tests performed on biaxially stressed coupons with the same shield configuration and standoff distance [1]. The depth of penetration for this impact ranged from 10 to $40 \%$ as was seen in the coupon HVI tests.

\section{Burst Pressure Testing}

The two damaged tanks (\#0062 and \#0092) and a third undamaged tank \#0251 were pressurized to burst at WSTF. As shown in Fig. 2, tank \#0251 failed at the ellipsoidal ends opposite of the hemispherical end that was targeted in the HVI tests. Tank \#0092 failed at the same ellipsoidal end as \#0251. However, Fig. 3 shows that tank \#0062 failed at the hemispherical end that was targeted and where excessive and unexpected damage occurred because of the late sabot separation. Moreover, the \#0062 tank failed at significantly lower pressure of 580 psig compared to tank \#0251 that failed at 795 psig and tank \#0092 at 785 psig.

The strain versus time history of tank $\# 0251$ during pressurization and up to the failure is shown in Fig. 4, while Fig. 5 shows the same data 
for tank $\# 0062$. From the strain-time history curve, it was apparent that the failure of tank \#0062 was preceded by a time interval of declining strain which could be caused by a slow depressurization of the tank. At about $575 \mathrm{sec}$, an abrupt decline in strain was observed similar to tank \#0251 at about $\sim 520 \mathrm{sec}$. However for tank \#0062, the interval between the peak strain and the abrupt decline in strain invited suggestions of slow damage progression (a stable crack growth process) before final failure.

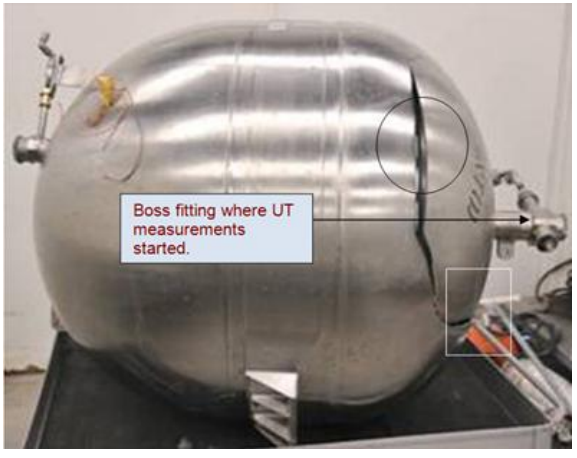

Figure 2. Tank \#0251failure at Ellipsoidal end. Tank \#0092 exhibited the same failure.

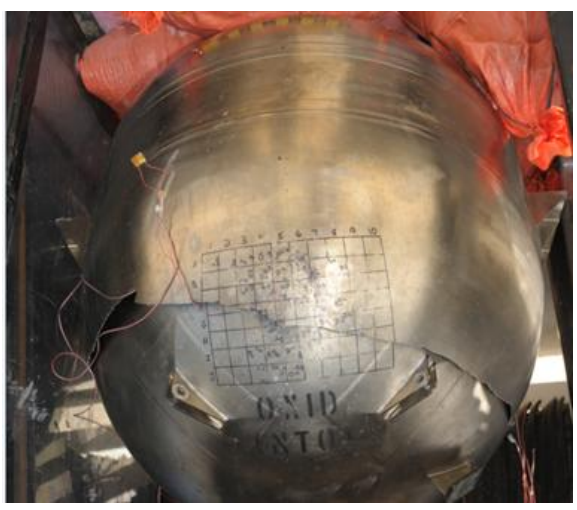

Figure 3. Tank \#0062 failure at the damaged area.

From a high speed camera recording at 800 frames/s, the tank unzipping was observed to occur in a time interval less than $12.5 \mathrm{~ms}$ which is the time duration between two consecutive frames. The high speed camera was only used in pressurizing tank \#0062, and therefore we could not evaluate the failure time scale of the other two tanks.
From the pressure-time curve of tank \#0062 and from a close examination of the crack line and a crater that exhibited spallation, it was suspected that the failure of tank \#0062 was due to crack propagation rather than a material failure due to loss of strength under the applied pressure. Tanks \#0251 and \#0092 on the other hand failed at significantly higher pressure such that the ultimate strength of Titanium was exceeded. For instance, at a pressure of 795 psig, the shell theory predicts a stress of about $149 \mathrm{ksi}$ which exceeds the titanium ultimate strength. This prompted the need for a linear fracture analysis to gauge the stress intensity factor and compare it to the titanium fracture toughness.

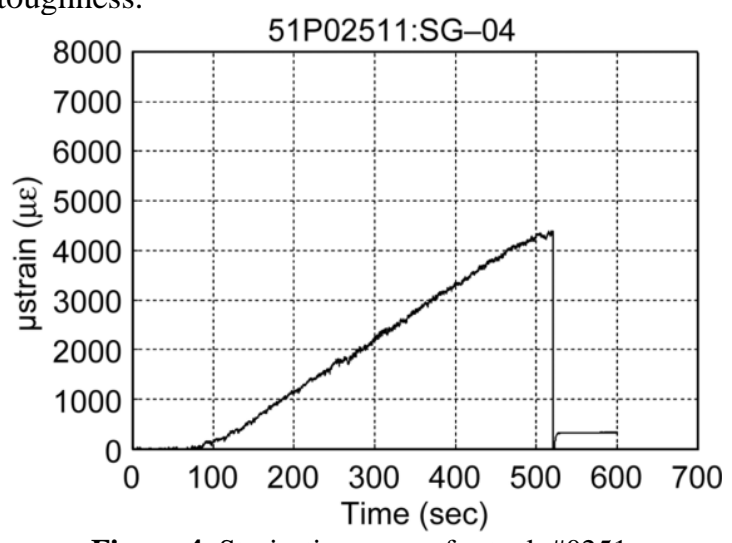

Figure 4. Strain-time curve for tank \#0251.

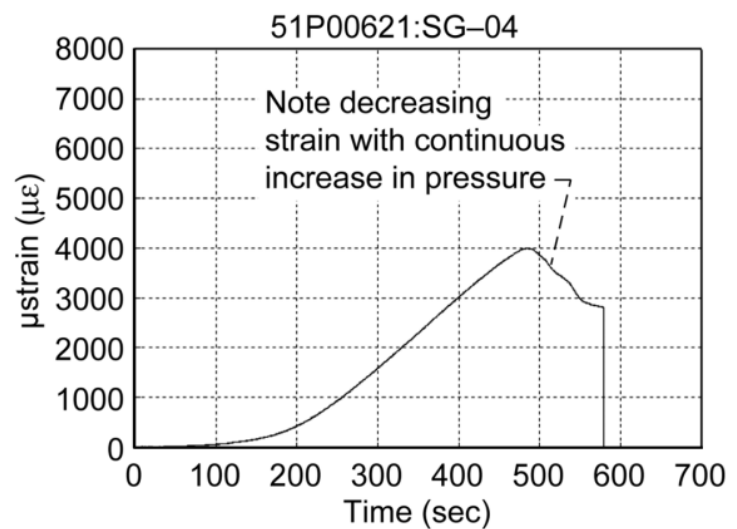

Figure 5. Strain-time curve for tank \#0062 that failed at the damaged area.

\section{Fracture and Finite Element Analyses}

A linear fracture mechanics analysis was performed on a spall crack that was detected in the process of examination of the crack line of tank 
\#0062 and that resulted from a secondary plume particle impact. The code NASGRO version 6.1 with routine $\mathrm{SC0} 3$ for external and internal cracks was used to perform this analysis. The formulation is based on the work of Newman and Raju, [2,3]. The option of internal crack was exercised in this calculation. The spall crack characteristics were measured from a higher magnification photograph obtained from the crack line. The crack depth was $0.0082 "$ and crack length $0.05 "$.

Based on the aforementioned internal crack characteristics and an internal pressure of $580 \mathrm{psig}$, the stress intensity factor was calculated and plotted as a function of the crack depth as shown in Fig. 6.

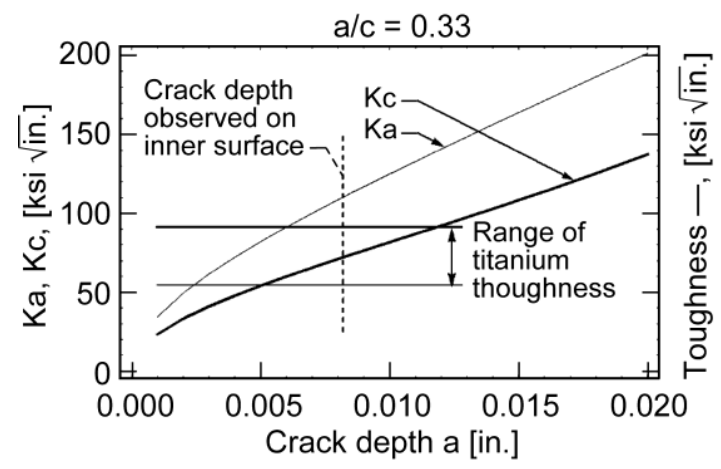

Figure 6. Calculated stress intensity factor and comparison with the Titanium toughness from literature.

For a crack depth of 0.0082", the stress intensity factor for crack depth-Ka exceeded the titanium toughness. This suggests that the failure may have been driven by fracture mechanics. The stress intensity factor for the crack length $\mathrm{Kc}$ for a crack depth of 0.0082 " fell in the middle of the Ti toughness range. This range was reported because we have not measured the toughness of the titanium used in the tanks.

To further corroborate the argument, a finite element analysis (FEA) on the tank was performed. For a pressure of 580 psi, the FEA showed in Fig. 7 that the Von-Mises stresses/criterion was below the yield limit of Ti-6Al-4V, yet the calculated stresses from the shell theory showed yield and ultimate strength exceedence at the higher burst pressures of tanks \#0092 and \#0125.

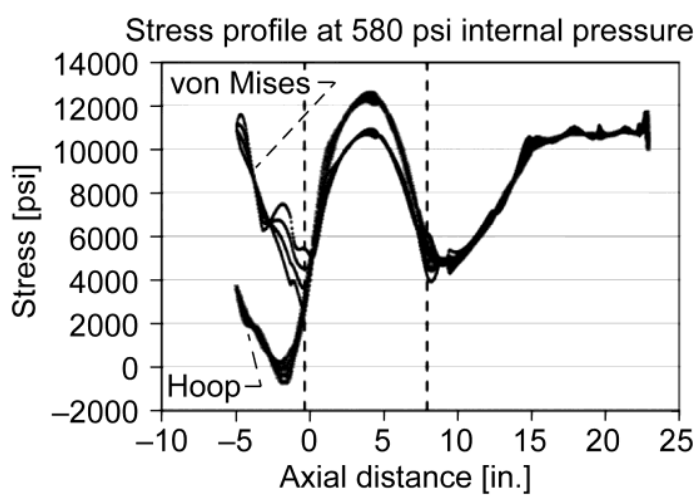

Figure 7. Finite Element Analysis of Ti tank at 580 psig.

\section{RECOMMENDATION}

Since spall cracks were suspected of resulting in the observed $27 \%$ reduction in the burst pressure of the tank, the recommendation is to limit the allowable depth of penetration that does not result in back spallations. This recommendation needs to be more specific based on pressure wall thickness, material and impact conditions. Future work encompasses a thorough evaluation of the $\mathrm{Ti}$ material strength and detailed look at the crack line with diagnostics such as Scanning Electron Microscopy and elemental analyses in order to assess the evidence of the stable crack propagation prior to final failure

\section{ACKNOWLEDGEMENTS}

The authors wish to thank the Orion Program for providing funding for this contribution.

\section{REFERENCES}

1. Nahra, H. K., et al., "Hypervelocity Impact of Unstressed and Stressed Titanium in a Whipple Configuration in Support of the Orion Crew Exploration Vehicle Service Module Propellant Tanks," NASA/TM-2010-216804.

2. Newman, J. C., and Raju, I. S., "Stress Intensity Factor Equations in Three Dimensional Finite Bodies Subjected to Tension and Bending Loads," Computational Methods in the Mechanics of Fracture, Elsevier Science Publishing Company, New York, NY 1986.

3. Anderson, T. L., "Fracture Mechanics Fundamentals and Applications," CRC Press 2000. 


\section{Burst Pressure Failure of Titanium Tanks Damaged by Secondary Plumes from Hypervelocity Impacts on Aluminum Shields}

Metallic pressure tanks used in space missions are inherently vulnerable to hypervelocity impacts from micrometeoroids and orbital debris; thereby knowledge of impact damage and its effect on the tank integrity is crucial to a spacecraft risk assessment. This paper describes tests that have been performed to assess the effects of hypervelocity impact (HVI) damage on Titanium (Ti) pressure vessels burst pressure and characteristics. The series consists of a pair of $\mathrm{HVI}$ impact tests on water-filled Ti tanks (water as a surrogate to the propellant) and subsequent burst tests of these tanks and an undamaged control tank. The tanks were placed behind Aluminum (Al) shields and then each was impacted with a $7 \mathrm{~km} / \mathrm{s}$ projectile. The resulting impact debris plumes partially penetrated the Ti tank surfaces resulting in a distribution of craters. During the burst tests, the tank that failed at a lower burst pressure did appear to have the failure initiating at a crater site with observed spall cracks. A fracture mechanics analysis that provides insight into how the cracks associated with a spall site initiate a failure cascade is discussed. 


\section{Burst Pressure Faillure of Titanium Tanks}

Damaged by Secondary Plumes from Hypervelocity Impacts on Aluminum Shields

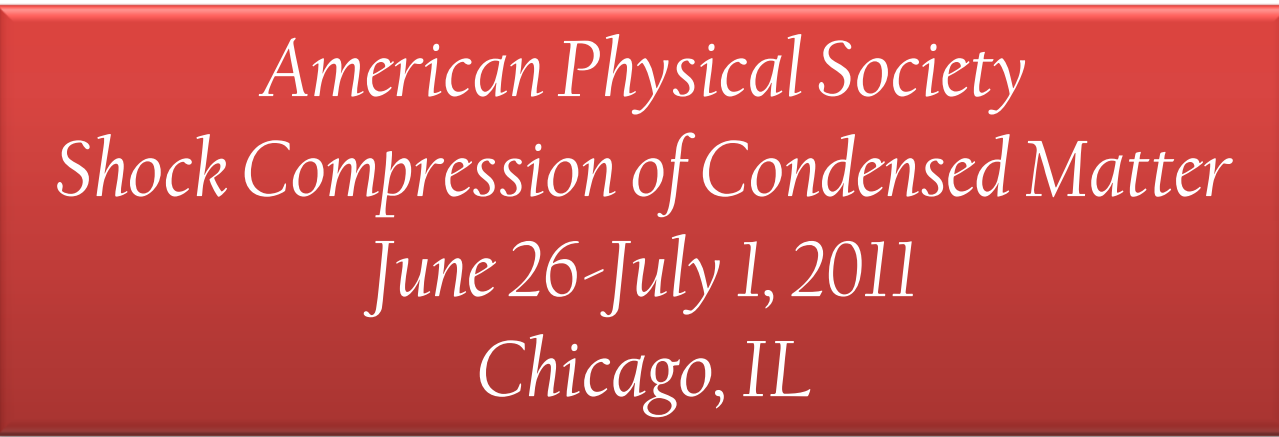

Henry Nahra, Louis Ghosn

Eric Christiansen, B. Alan Davis

Chris Keddy, Karen Rodriguez Joshua Miller, William Bohl
NASA-Glenn Research Center

NASA Johnson Space Center

White Sands Test Facility

Lockheed Martin Space Systems Company 


\section{Contribution Highlights}

O Objective

- Assess the titanium tanks burst pressure after experiencing partial penetration from the plume generated from a hypervelocity impact on an aluminum shield.

- Based on burst pressure testing of two shielded Ti $6 \mathrm{Al} 4 \mathrm{~V}$ tanks damaged by the Aluminum shield plume, and one undamaged tank,

- This work suggests that the failure of one tank (0062) was due to a spall crack induced by crater that formed from the impact of the plume on the Ti tank surface.

$>$ Tank 0062 burst pressure was lower than other two tanks

$>$ At burst pressure Von-Mises stresses were lower than the yield stress

$>$ The stress intensity factor was greater than the Ti alloy toughness

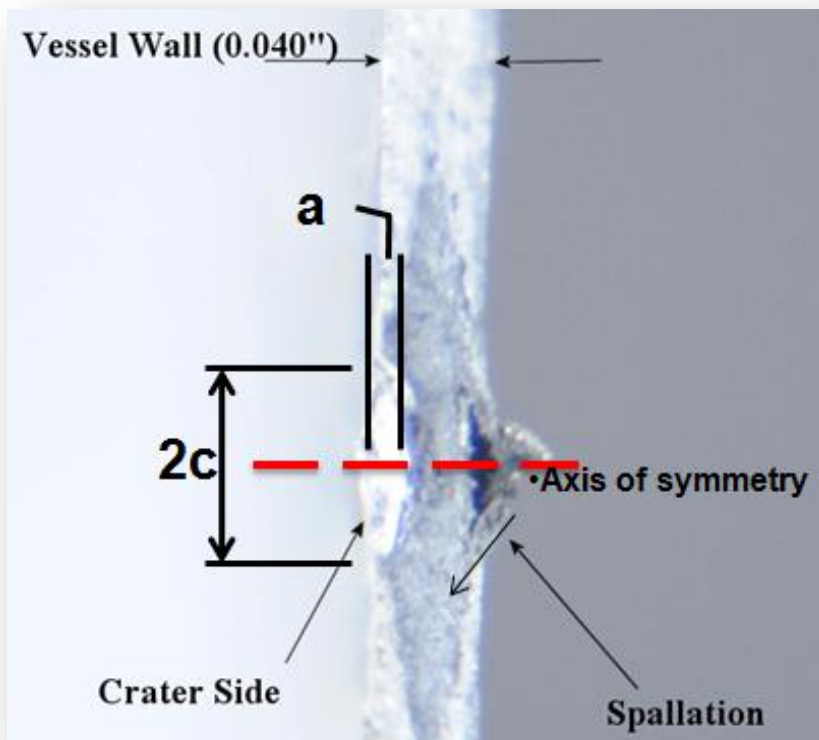




\section{Background, Objective and Approach}

- Background

- Establish through a well coordinated effort, a process to determine/assess

Micrometeoroids and Orbital

Debris damage criteria on metal and composite pressure vessels

- Phase-I addresses and concentrates on the metallic pressure vessels MMOD driven failure criteria

- Phase II addresses and concentrates on the composite overwrap pressure vessels (COPV) failure criterion

\section{- Approach}
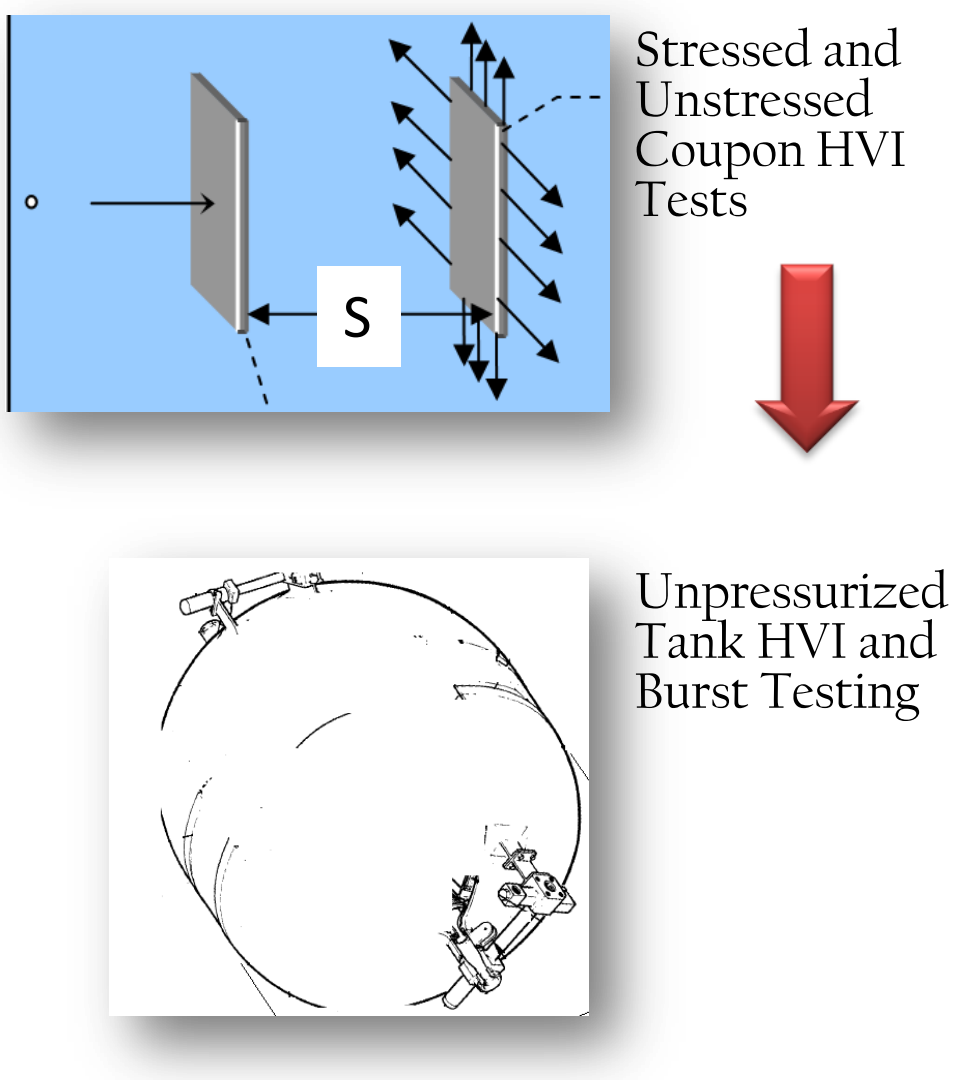


\section{Hypervelocity Impact Test Article}

\section{Test Article}

- Launched projectile penetrates a 0.04" aluminum plate

- The plume emanating from the first projectile-aluminum plate interaction bombards the titanium dome surface and produces a spectrum of partial penetrations on the dome surface.

\section{Test Conditions}

- Two Tanks were impacted with a hypervelocity projectiles

- Thickness scan performed on the two HVI test tanks

- The two tanks were unpressurized when HVI tested

Table 2. Shows the Minimum success criterion test matrix for the Titanium tank HVI tests

\begin{tabular}{|c|c|c|c|c|c|}
\hline $\begin{array}{c}\text { Test } \\
\text { Number }\end{array}$ & $\begin{array}{c}\text { Projectile } \\
\text { Diameter } \\
(\mathrm{mm})\end{array}$ & $\begin{array}{c}\text { Projectile } \\
\text { Materials }\end{array}$ & $\begin{array}{c}\text { Requested } \\
\text { Velocity } \\
(\mathrm{km} / \mathrm{s})\end{array}$ & $\begin{array}{c}\text { Impact } \\
\text { Angle } \\
(0\end{array}$ & Comments \\
\hline \hline \multicolumn{6}{|c|}{ Impact on Shielded Tank Dome Surface } \\
\hline \hline 3 & 1.6 & A1 2017-T4 & 7.0 & 0 & $\begin{array}{l}\text { Partially filled with water. Estimated average } \\
\text { DOP of } 10 \%, \text { Range } 5 \text { to } 21 \% \S\end{array}$ \\
\hline 6 & 3.6 & Nylon & 7.0 & 0 & $\begin{array}{l}\text { Partially filled with water. Estimated average } \\
\text { DOP of } 20 \%, \text { Range from } 11 \text { to } 37 \% \S\end{array}$ \\
\hline
\end{tabular}

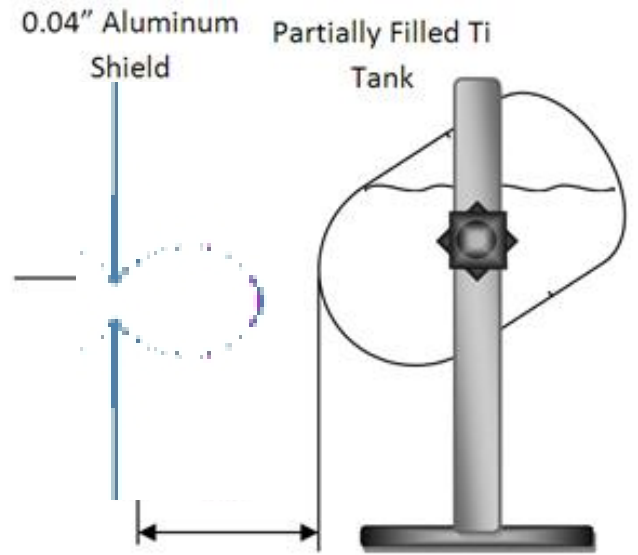

$1.6 \mathrm{~mm}$ Aluminum Projectile

$3.6 \mathrm{~mm}$ Nylon

projectile 


\section{Damage Distribution and Characteristics}

- Damage Distribution of Tank 0062 caused by $1.6 \mathrm{~mm} \mathrm{Al}$ projectile and Sabot pieces

- Exhibits two areas of damage which may have been caused by the sabot piece impacting the $\mathrm{Al}$ shield

- Distribution exhibited deeper than expected impacts

- Damage Distribution of Tank 0092 caused by $3.6 \mathrm{~mm}$ Nylon projectile

- Exhibited Uniform damage distribution as seen in stressed and unstressed coupon HVI tests

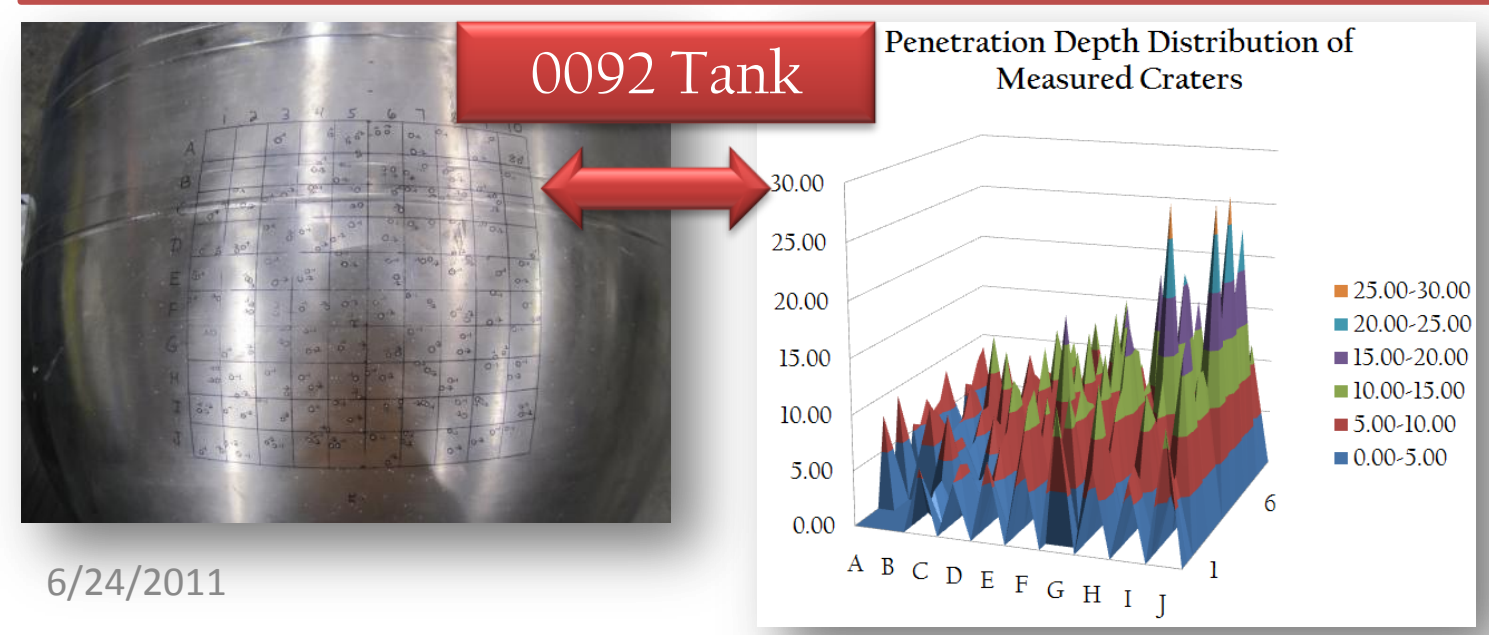

Depth Distribution of Measured Craters

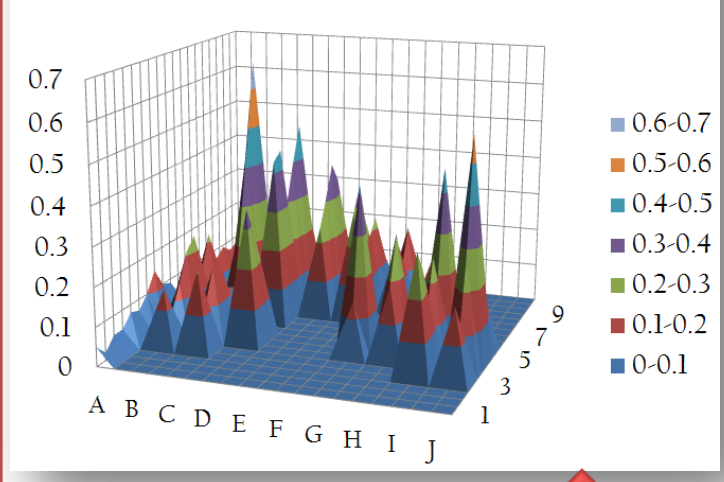

\section{Tank}

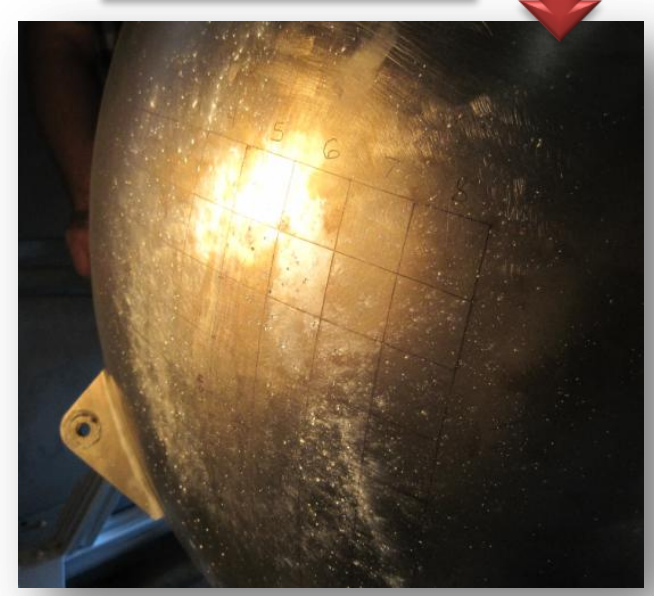




\section{Post Impact Burst Testing}

- One pristine and the two HVI damaged tanks were pressurized to burst

- Data included Pressure-Time, High and normal Speed video

- The remaining two (undamaged and damaged tanks) failed at the elliptic end. [Fig. A]

- Tank SN 51 P0062 failed at the impacted area [Fig. B \& C].

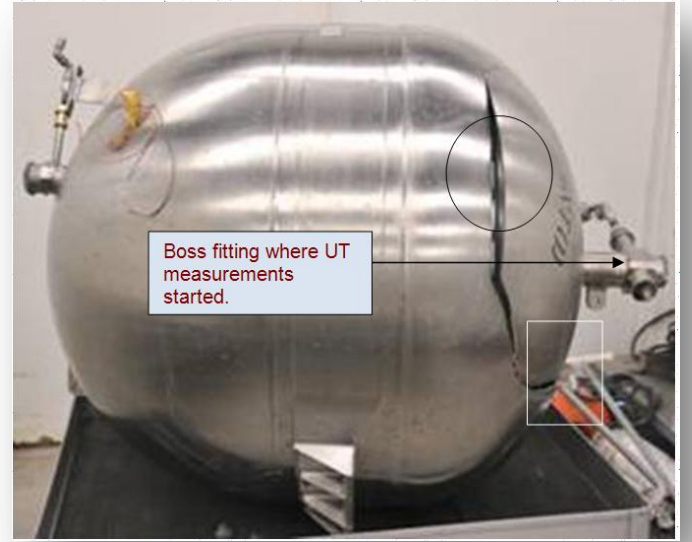

A-Tanks P025l P0092 failed at Elliptic end

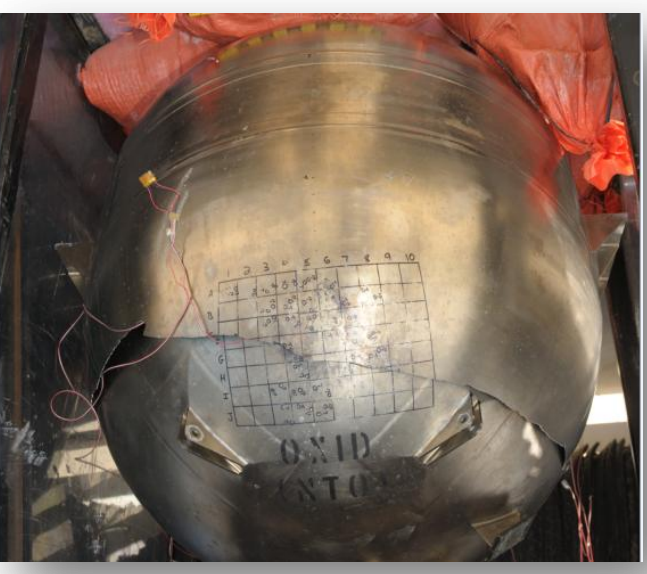

B-Tank with crack shown in the impacted area

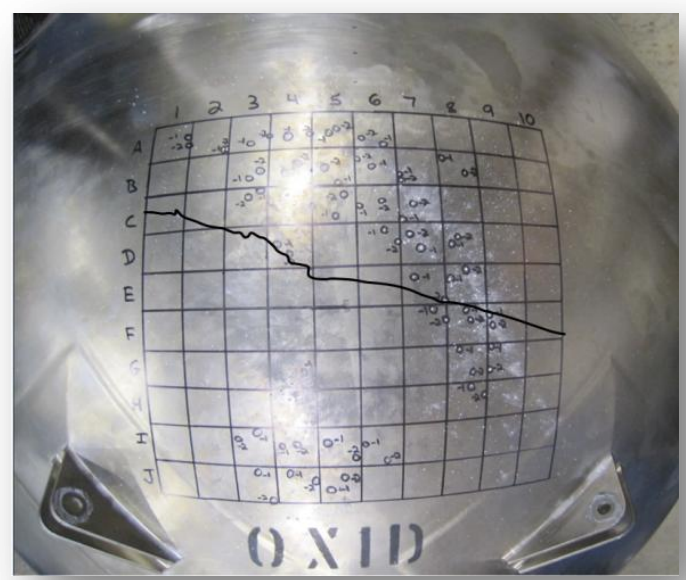

C-Crack line superimposed on tank 


\section{Pressure and Strain Data}
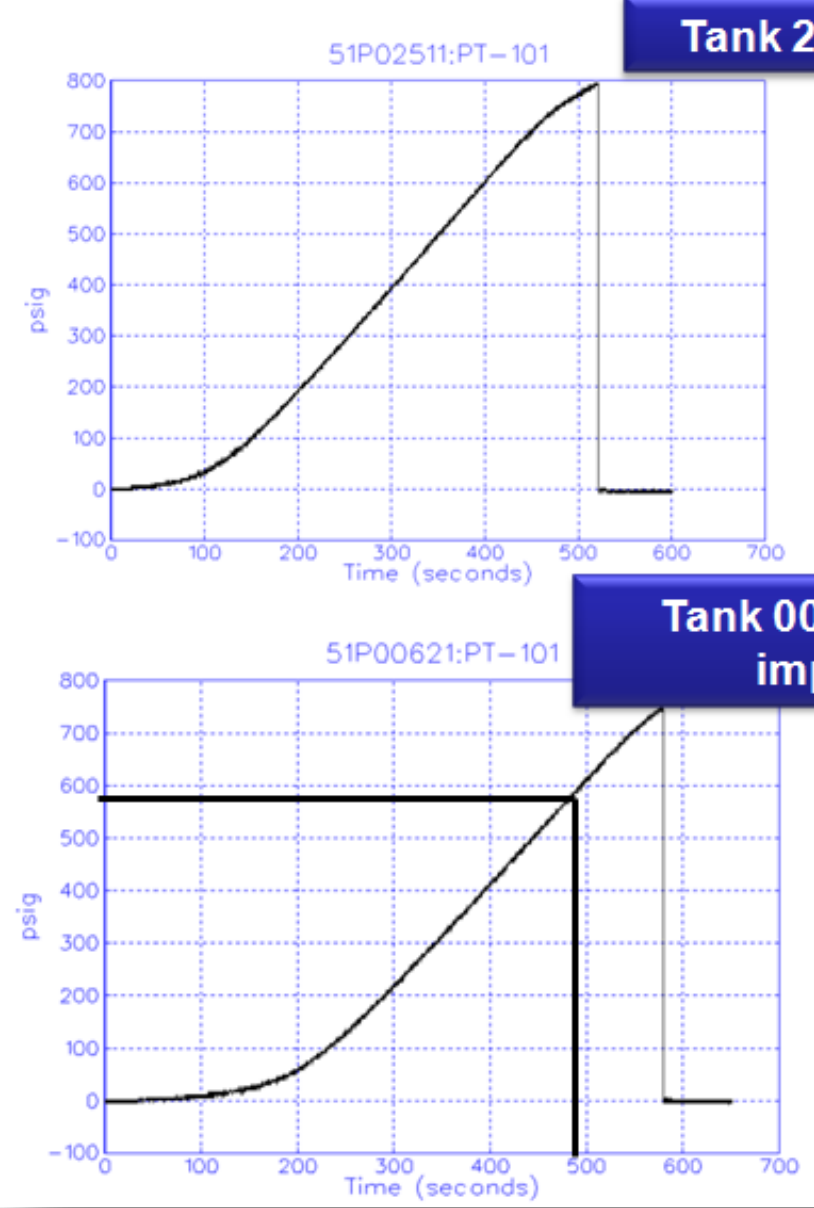

Tank 251 Baseline
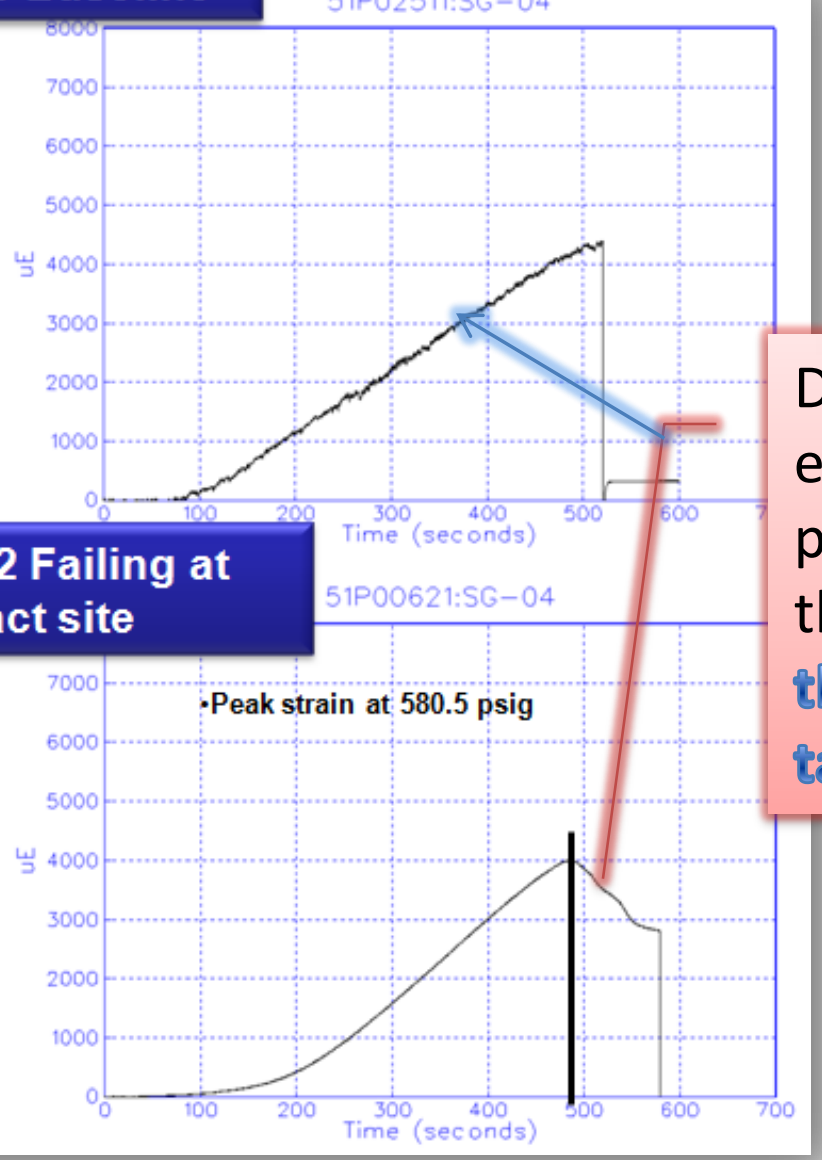

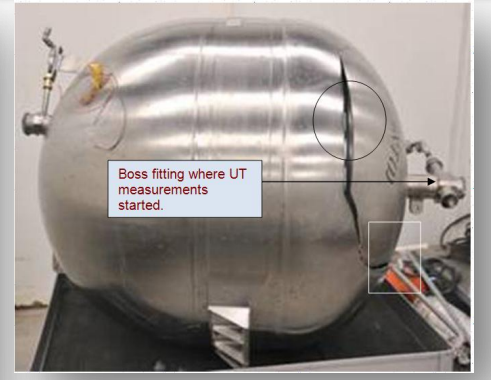

Decrease in strain eluding to a relief process followed by the tank failure. Note the difference with tank 251

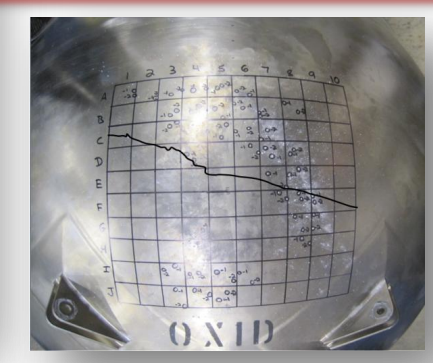

Failure of Tank 0062 could have been induced by a crack propagation 


\section{Approach to Failure Analysis}

- Determination of the failure mode of the tank under burst pressure

- Failure caused by loss of strength

- Failure cause by dynamic crack propagation

- Perform a fracture analysis and compare toughness of Titanium with the predicted stress intensity factors

- On the inside surface where a spall has been observed

- $\mathrm{a}=0.0082 ", 2 \mathrm{c}=0.05$ ",

- $c=0.025 "$

- $\mathrm{a} / \mathrm{c}=0.33$

- Used NASGRO to compute the stress intensity factor and compared with the Titanium toughness

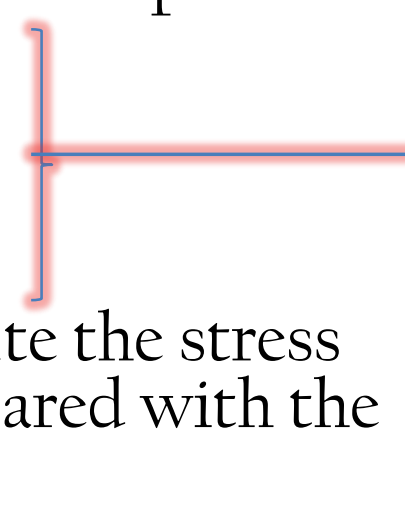

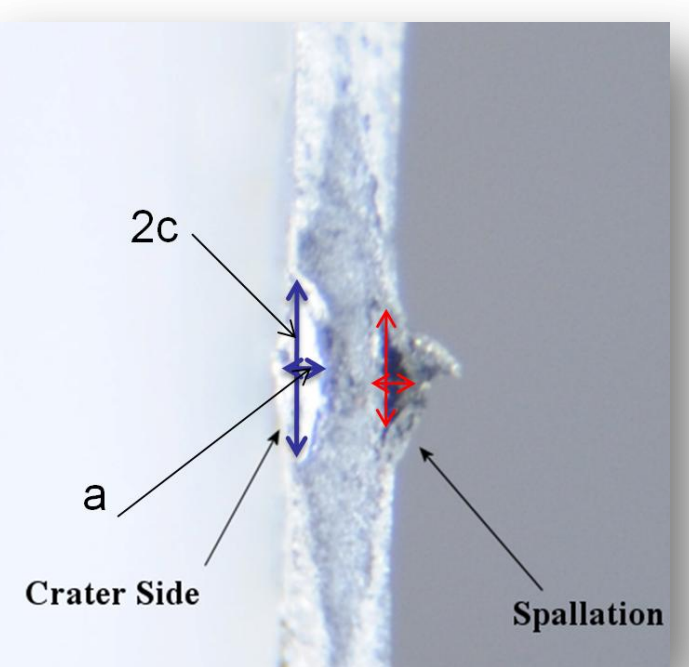

\section{$\mathrm{SC03}$}

internal or external crack

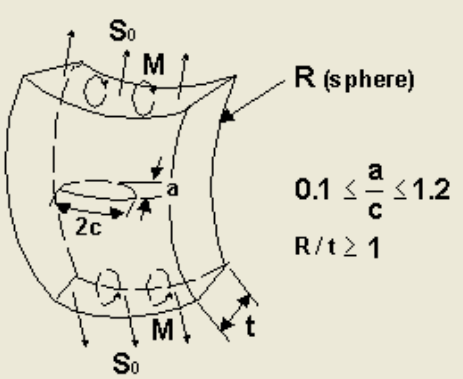
$S_{1}=\frac{6 M}{W^{2}} \quad S_{4}=\begin{aligned} & \text { crack face pressure, only } \\ & \text { for internal crack }\end{aligned}$

Note: If stresses are input via a long block format, S4 values must use columns 6 and 7 , (which is not used for this case). 


\section{Linear Fracture Analysis}

- At the observed crack depth of 0.0082"

- Ka exceeds the maximum Ti toughness

- Kc matches the middle of the Ti toughness of $-70 \mathrm{ksi}-\mathrm{in}^{1 / 2}$.

- This suggests that a crack opening from the internal pressure occurred and perhaps the crack initiation was due to the spallation

Need to look at the area of crack to see any traces of crack propagation and propagation speed

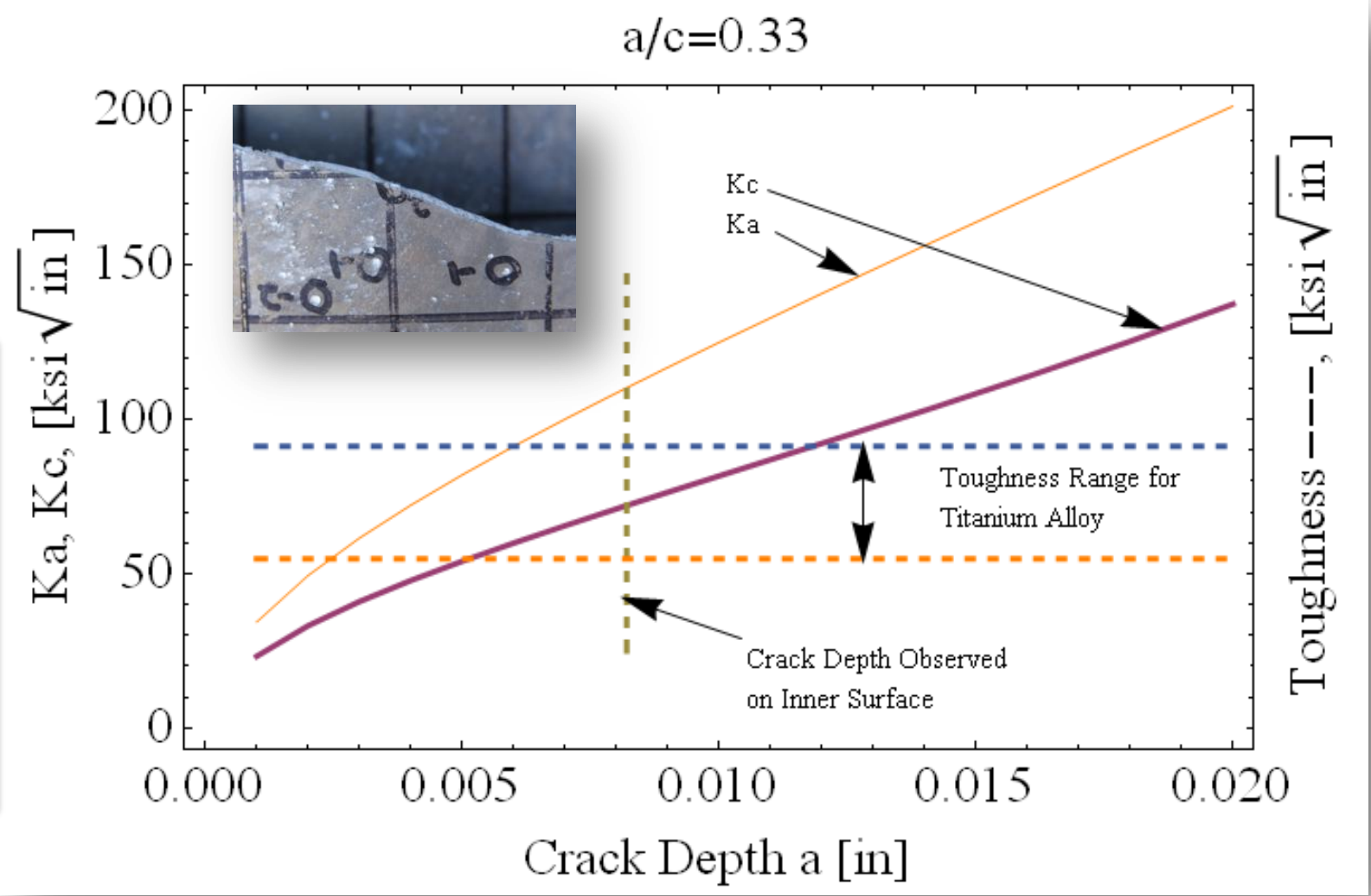




\section{Analysis}

- A plastic-elastic axi-symmetric finite element analysis was performed on the tank with a $\mathrm{x}-\mathrm{y}$ coordinates provided from the thickness profile

- Pressure in tank assumed at 580 psi

- Yield strength at $125 \mathrm{ksi}$

- Ultimate strength at $145 \mathrm{ksi}$

- Results show that at 580 psi, the hoop and Von Mises stresses are below the ultimate the yield strength of $\mathrm{Ti} 6 \mathrm{Al} 4 \mathrm{~V}$

- This corroborates the findings that failure at 580 psi was caused by a crack propagation and was not driven by strength exceedence

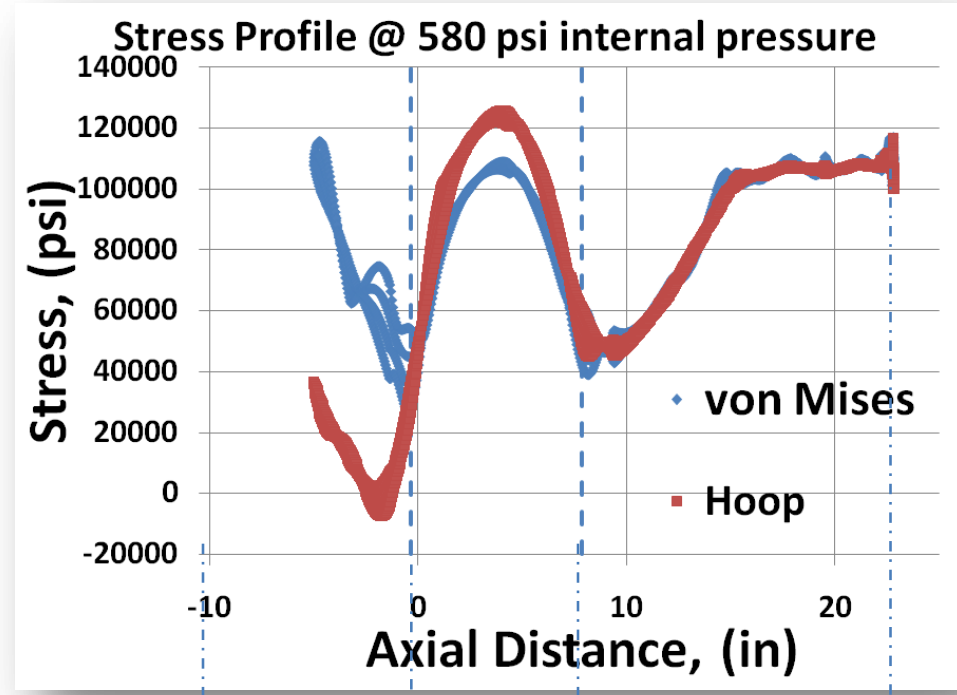




\section{Consequence of Rupture-Measurement of Fluid Velocity}

- Fluid Velocity Measurements from high speed video

- Flow upon crack opening accelerated and then reached a reasonably constant velocity of $-17 \mathrm{~m} / \mathrm{s}$

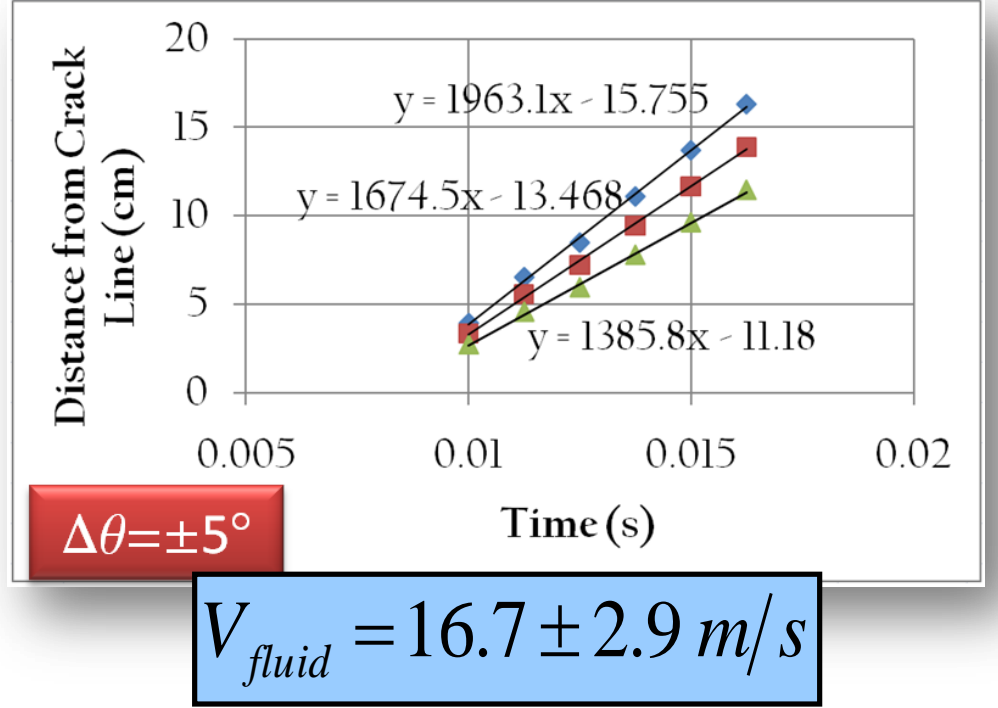

- Concerning is the quick dispersion of highly reactive propellant, contact with other nearby hardware and the resulting consequences of such a contact

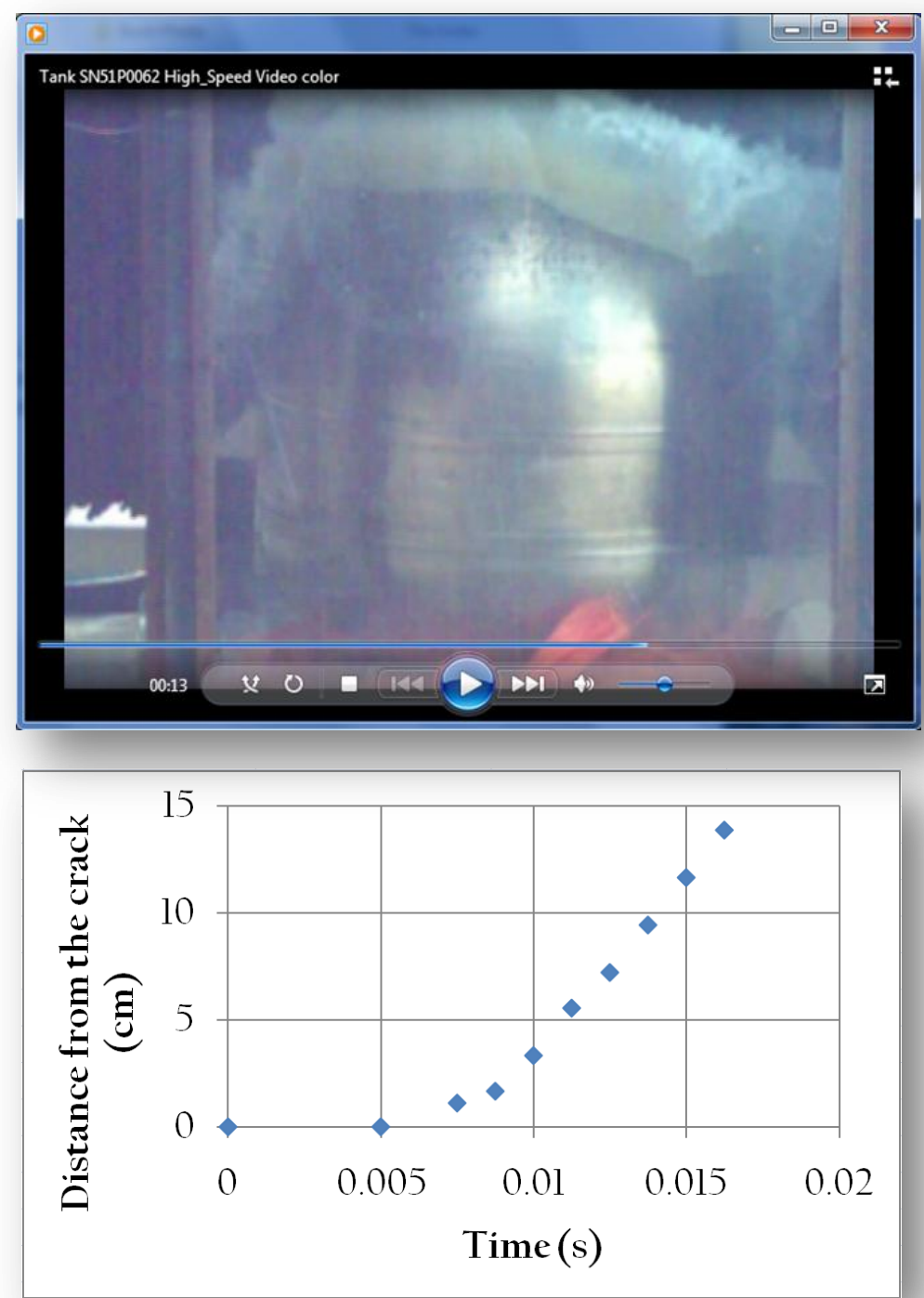




\section{Conclusions and Recommendations}

\section{Conclusions}

$>$ Failure of the damaged tank 0062 is induced by a spall crack that propagated and resulted in the tank rupture at lower pressure

$>$ Failure of the two tanks that ruptured at the ellipsoidal ends may have been induced by an exceedence of the ultimate strength of Ti where significant stresses were experienced in the area of smallest Ti thickness

- For the burst pressure of 795 psig, the estimated stresses at the thinner boss area exceeded the ultimate strength of $\operatorname{Ti}\left[\sigma_{\text {Calc. }} \sim 149 \mathrm{ksi}\right.$ compared to $\left.\sigma_{\mathrm{u}} \sim 130-145 \mathrm{ksi}\right]$

\section{Recommendations}

$>$ Based on this limited work, it is recommended that:

- The allowable crater depth (failure criterion) must not result in a spall on the back/inner surface exposed to the tank pressure.

\section{Future Work}

- Take a closer look at the crack lines on tanks that failed at the elliptic end away from the impacted area

- Look for crack evidence and propagation

- Residual Strength and stress-strain curve measurements for higher fidelity finite element modeling of the Ti tank with damage modeling 


\section{Potential Future Work}

- This effort stems from a program whose objective is to establish the allowable depth of penetration from hypervelocity impacts on metallic and composite surfaces.

- Application to space programs and specifically Orion Service module propellant and pressure tanks

- The program was partially funded

- Blue boxes in flow chart have been completed

Acknowledgement

The authors thank the Orion Crew and Service Module Program for funding this activity. The authors thank the HITF group at JSC for the testing and data analyses performed on the Titanium samples.
Phase 1/Task 1

Coupons testing on Metallic surfaces

Phase 1 /Task 2

Metallic Tank HVI Testing

Results Comparison between tank and coupon testing

Define penetration criteria for metal tanks
Post Impact Analyses Profilometry, Micromechanical, Residual Strength

Post Impact Analyses Profilometry, Micromechanical, Residual Strength

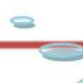

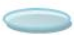

We are here

q Similar effort can be applied to COPVs.

- A plan in place to assess the allowable depth of penetration on COPVs using a building block approach. 